\title{
Effect of spatial variability on undrained triaxial test of cement-admixed soil
}

\author{
Pan Yutao ${ }^{\text {i) }}$, Lee Fook Hou ${ }^{\text {ii), }}$ Liu Yong ${ }^{\text {iii) }}$ and Xiao Huawen ${ }^{\text {iii) }}$
}

\begin{abstract}
i) Ph.D Student, Department of Civil and Environmental Engineering, National University of Singapore, Kent Ridge, Singapore. ii) Professor, Department of Civil and Environmental Engineering, National University of Singapore, Kent Ridge, Singapore. iii) Research Fellow, Department of Civil and Environmental Engineering, National University of Singapore, Kent Ridge, Singapore.
\end{abstract}

\begin{abstract}
The material properties of cement-admixed soil vary spatially. Statistical parameters such as mean, coefficient of variation and scale of fluctuation were used to characterize the spatial variability of cement-admixed soil. In this paper, an advanced constitutive model for cement-admixed marine clay is firstly randomized by relating model parameters to mix ratios and hence binder concentration. This makes it possible to estimate behavior of spatially varying cement-admixed soil before construction. Then a random finite element analysis with fully-coupled consolidation analysis is performed to simulate the undrained behavior of cement-admixed soil with spatially varying properties in specimen-scale. Results show that existence of spatial variability reduces the overall strength of specimen and a "worst case" occurs when SOF is approximately one third of the diameter of specimen.
\end{abstract}

Keywords: cement-admixed soils; spatial variability; undrained triaxial test; finite element method.

\section{INTRODUCTION}

It has been observed that, regardless of the method used to introduce cement into soil, the resulting admixture exhibit non-uniformity (e.g. Larsson et al., 2005a, 2005b; Chen et al., 2011; Namikawa and Koseki 2013) which has significant implications in design and construction. Back-analysed field data indicate significantly lower mobilized mass properties than laboratory measured values for the given mix ratio (Shikauchi et al., 1993; Nakagawa et al., 1996) or the elemental properties obtained from the vertically cored samples (O'Rourke et al., 1998; Pickles and Henderson, 2005). To achieve the benefit of ground improvement while keeping sufficient safety margin, an evaluation of effect of spatial variability on mobilized shear strength is required.

Spatial variability of soils can be characterized by a second-order random field (Vanmarcke, 1977). In particular, this type of random field can be generally specified by a marginal distribution and a scale of fluctuation (SOF) for geomaterials (Phoon and Kulhawy, 1999). Normal and lognormal distributions are often used to characterize property field of soil (e.g. Nour et al., 2002; Fenton and Griffith, 2003). Probabilistic studies (Honjo, 1982; Matsuo, 2002; Futaki and Tamura, 2002; Omine et al., 2005) have been carried out to account for variability of soil into design. However, the effect of SOF on mobilized shear strength was not considered in these studies.

To account for the effect of both distribution and SOF, many studies investigated mobilized shear strength of soil by using random finite element analysis (RFEA) (e.g. Kim and Santamarina, 2008; Namikawa and Koseki, 2013; Ching and Phoon, 2013; Liu, 2013). Namikawa and Koseki (2013) performed a RFEA on field-scale to investigate the effect of spatial correlation to mobilized shear strength of a single cement-treated column. Ching and Phoon (2013) also used the RFEA to analyze the mobilized shear strength on meso-scale. However, most of these studies used linear elastic model or elastic perfectly plastic models. The elastic perfectly plastic model is unlikely to model the full range of behavior of cement-admixed soil (Hight et al., 2005) though it is widely used in design. Kim and Santamarina (2008) performed RFEA to study spatial variability on drained and undrained deviatoric load response of soil using Modified Cam Clay model. However, the soil is non-cohesive which is quite different from cement-admixed soil.

In recent years, several advanced constitutive models for cement-treated soil have been developed (e.g. Namikawa and Koseki, 2007; Horpibulsuk et al., 2010; Suebsuk et al., 2011; Xiao, 2009). These models have been developed to model the behavior of cementadmixed soil with cement content up to about $20 \%$. In ground improvement works for deep excavation, much higher cement content (up to 100\%) is often used. Xiao (2009) has noted that, since none of these models incorporated any change in the shape of the yield locus, they are unlikely to describe the constitutive behavior of cement-treated soil with high cement content. To investigate the mobilized shear strength of cement- 
admixed soil, a randomized version of Xiao's (2009) constitutive model for cement-admixed soil is required. This is the aim of this study. Since many factors may influence the variability and hence mobilized shear strength of cement-admixed soil, the study begins with the effect of random variation within a specimen.

Even in specimen scale, the spatial variability of specimen is likely to happen. In Xiao's (2009) experiment, the cement and marine clay was mixed in a Hobart mixer for about 10 minutes. The mixing time is much shorter than that used for clay beds in centrifuge model tests, which is typically several hours. The reason for this discrepancy is that cement-treated clay starts to harden once it is mixed; this is different from untreated clay which does not undergo any chemical reaction. Hence, the mixing time had to be kept short. In addition, the Hobart mixer does not have facility to apply vacuum during mixing. There may still be weak zones (for example, microscopic air bubbles or regions with relatively low cement content) in samples though the samples are usually carefully treated. Hence, nonuniformity and air bubbles may still exist after mixing. During primary loading, these weak zones may yield before the whole sample yields. As a result, some yielding may occur although the specimen is within the yield surface.

In this paper, the constitutive model for cementadmixed soil (Xiao, 2009) is randomized using available relationship or test data. The effect of spatial variability on undrained triaxial test is investigated.

\section{RANDOMIZATION OF XIAO'S MODEL}

\subsection{Identification and Characterization of Basic Random Variable}

In many uni-variate RFEA studies, a "basic" random variable is usually selected so that other parameters of the constitutive are obtained by empirical or assumed relations. Basic random variables used include elastic modulus (e.g. Paice, et al., 1996; Fenton and Griffiths, 2002), cohesion or friction angle (e.g. Fenton and Griffiths, 2003), unconfined compressive strength $\left(q_{\mathrm{u}}\right)$ (e.g. Namikawa and Koseki, 2013; Liu, 2013) or undrained shear strength (e.g. Griffiths and Fenton, 2004; Nobahar and Popescu, 2001; Ching and Phoon, 2013). The above parameters can only be obtained from coring samples after construction. On the other hand, there are benefits to be accrued if the behavior of a cement-admixed soil mass can be estimated based solely on mix proportion, at design stage.

In wet mixing, the two components of cementadmixed soil are cement slurry and natural soil. The cement binder is usually mixed in mixing plants and uniformity is often easy to ensure. Hence the spatial variability of cement-admixed soil is likely to be contributed by inherent spatial variability of natural soil and the ratio of cement slurry to natural soil. However, the SOF of natural clay properties was estimated to be $10 \sim 10^{2} \mathrm{~m}$ in horizontal direction and $10^{-1} \sim 10^{1} \mathrm{~m}$ in the vertical direction (Phoon and Kulhawy, 1999) which is far larger than observed scales of fluctuation in cementtreated soil mass (e.g. Larsson, 2005a; 2005b). Hence it is reasonable to assume the spatial variability of cement-admixed soil is caused mainly by spatial variation in the proportion of cement binder to natural soil. The ratio of cement slurry to the final mixture of cement-admixed soil by weight is defined as binder concentration (Chen, 2012).

$$
c_{\text {binder }}=\frac{W_{\text {slurry }}}{W_{\text {mixture }}}
$$

where $\mathrm{w}_{\text {slurry }}$ is the weight of cement slurry and $\mathrm{w}_{\text {mixture }} \mathrm{i}$ $\mathrm{s}$ the weight of final mixture of cement-admixed soil.

This is not surprising since the mixing is invariably conducted in-situ in underground cavity and uniformity cannot be ensured. In this paper, the effect of variation $i$ $\mathrm{n}$ the proportion of cement binder within a specimen is considered.

With the binder concentration and parameters of ce ment binder (e.g. cement content of cement binder) and natural soil (e.g. natural water content of soil), the final mix proportion of cement-admixed soil can be determin ed from a physical phase relationship (Chen, 2012). In t his study, the mix ratio of final cement-admixed soil is $r$ epresented by soil mass ratio: soil: cement: water (s: c: w) by weight, following Xiao (2009). In terms of the mi $\mathrm{x}$ ratio, the cement content is $\frac{c}{s}$ and the water content of the mix is $\frac{w}{s+c}$. For example, a 10:3:13 cement-admixed denotes a cement-admixed soil with soil-to-cement rati o of 10/3 and water-to-cement ratio of $13 / 3$, which is eq uivalent to a cement content of $30 \%$ and a water conten $t$ of $100 \%$. If the soil: cement ratio is denoted as $\mathrm{x}$ and water: cement ratio is denoted as $y$, then

$$
\begin{aligned}
& x=\frac{1+\Lambda}{1+w}\left(\frac{1}{c_{\text {binder }}}-1\right) \\
& y=w x+\Lambda \\
& \Lambda=\frac{G_{\mathrm{c}} \rho_{\mathrm{w}}-\rho}{G_{\mathrm{c}}\left(\rho-\rho_{\mathrm{w}}\right)}
\end{aligned}
$$

$c_{\text {binder }}$ - binder concentration, defined as the ratio of cement slurry to the final mixture by weight.

$\Lambda$ - water-cement ratio by weight in slurry,

$G_{c^{-}}$specific gravity of cement powder,

$\rho$ - density of cement slurry, unit $\mathrm{g} / \mathrm{cm}^{3}$,

$\rho_{\mathrm{w}}$ - density of water, unit $\mathrm{g} / \mathrm{cm}^{3}$,

$w$ - natural water content.

The strength and compressibility of cementadmixed soil are mainly influenced by cement content, water content, curing stress, curing temperature and curing time (Uddin et al., 1997; Rotta et al. 2003; Lorenzo and Bergado, 2004; Xiao, 2009). Within a specimen, the difference in curing stress, curing 
Table 1 Material Parameters for Cement-admixed Soil

\begin{tabular}{ccccccccccc}
\hline Parameters & $\kappa_{\mathrm{s}}$ & $\lambda_{\mathrm{u}}$ & $M$ & $a$ & $b$ & $a_{1}$ & $b_{1}$ & $p_{\text {py }}^{\prime}$ & $C_{0}$ & $\mu^{\prime}$ \\
\hline Remarks & Deter. & Deter. & Deter. & Deter. & Deter. & Deter. & Deter. & Rand. & Rand. & Deter. \\
Value & 0.016 & 0.30 & 1.7 & 4.7 & 2.13 & -0.705 & 0.045 & - & - & 0.2 \\
\hline
\end{tabular}

Note: Deter. $=$ deterministic; Rand $=$ random temperature and curing period is likely to be negligible. This is because the difference in confining pressure is very small due to its small dimension and the same batch of specimens is cured under a very similar curing period and temperature. Hence the property difference of cement-admixed soil from point to point is probably contributed mainly by the variation in mix proportion. Therefore, one can determine the property of one point once the local mix proportion is given.

\subsection{Randomization of Model Parameters}

Xiao et al. (2014) provided empirical relationships which enable several of the parameters to be related to the mix ratio. Given soil to cement ratio $(x)$ and water to cement ratio $(\mathrm{y})$, one can obtain $p_{\text {py }}^{\prime}$ and $C_{0}$ in Xiao's constitutive model via following relationship (Xiao, 2009 and 2014).

The primary yield stress can be obtained from Xiao et al. (2014),

$$
p_{\text {py }}^{\prime}=22360\left\{1-\frac{1}{1+(0.0325 t)^{0.52}}\right\}\left\{\frac{\mathrm{e}^{0.3 x}}{y^{2.92}}\right\}+\left\{1+\frac{5.04}{x}+\frac{12.30}{x^{2}}\right\} p_{\text {cur }}^{\prime}
$$

Similarly, unconfined compressive strength is also given in Xiao et al. (2014)

$$
q_{\mathrm{u}}=q_{\infty}\left\{1-\frac{1}{1+\left(\frac{\alpha t}{q_{\infty}}\right)^{\gamma}}\right\}\left\{\frac{\mathrm{e}^{m x}}{y^{n}}\right\}+\left\{\frac{C_{2}}{x}+\frac{C_{1}}{x^{2}}\right\} p_{\text {cur }}^{\prime}
$$

where $q_{\infty}=40000 \mathrm{kPa}, \quad \alpha=1300 \mathrm{kPa} /$ day , $\gamma=0.52, m=0.3$ and $n=2.92, C_{1}=22$ and $C_{2}=$ 9 for 7 - day curing time.

$C_{0}$ was found to be closely related to $q_{\mathrm{u}}$ in Xiao (2009),

$$
C_{0}=0.95 q_{\mathrm{u}}
$$

Xiao's model (2009) can be randomized because several of the parameters have already been related to mix ratio and hence binder concentration, Eqs. (5-7). However, for the present, in order to randomize the model while making the most of existing data, some simplifications are made herein.

From a physical point of view, some parameters should vary with mix proportion. For example, the swelling index of the intact improved soil $\kappa_{\mathrm{s}}$ vary with mix ratio since the stiffness usually increases with degree of structure which is closely related to mix ratio. However, to make the problem tractable, only $p^{\prime}$ py and $C_{0}$ are assumed to vary with mix ratio while other parameters are kept constant. Similar assumptions are adopted by other researchers (e.g. Namikawa \& Koseki,
2013; Kim \& Sanatamrina, 2008 and Liu, 2013) when randomizing complex constitutive models, for which the parameters have not been fully correlated. In Namikawa and Koseki (2013)'s study, important parameters such as friction angle and dilatancy coefficient are assumed to be constant. Kim and Santamarina (2008) also assumed the initial void ratio to be the random variable while other parameters such friction coefficient and Poisson's ratio are assumed to be constant.

In sum, to randomize the constitutive model, the important parameters ( $p_{\text {py }}^{\prime}$ and $C_{0}$ ) can now be obtained from mix proportions via Eqs. (5) (7) and other parameters are assumed to be constant and take average values of test data. The mix proportion can be further linked to binder concentration via Eqs. (2) (4). The model parameters are listed in Table 1 . The values are obtained from Xiao and Lee (2014).

\subsection{Simulation of Spatial Variability of binder concentration in Finite Element}

Both normal and lognormal distributions are widely used to characterize random parameters in RFEA in geotechnical research (e.g. Namikawa, 2013; Ching and Phoon, 2013; Griffiths and Fenton, 2009). Larsson (2001) reported that the binder concentration follows a normal distribution in well-mixed lime-treated columns. Chen $(2011,2012)$ reported that a truncated normal distribution fits the distribution of binder concentration well. In this study, the normal distribution of binder concentration is assumed.

The auto-correlation function is assumed to be squared exponential model:

$$
\rho(\Delta h, \Delta v)=\exp \left[-\pi\left(\frac{\Delta h}{\delta_{\mathrm{h}}}\right)^{2}-\pi\left(\frac{\Delta v}{\delta_{\mathrm{v}}}\right)^{2}\right]
$$

where $\Delta \mathrm{h}$ and $\Delta \mathrm{v}$ are horizontal and vertical distances from the interested point; $\delta_{\mathrm{h}}$ and $\delta_{\mathrm{v}}$ are horizontal and vertical SOFs. In this study, $\Delta h=\Delta v$ is adopted to represent a statistically homogeneous material.

In this study, the binder concentration $c_{\text {binder }}$ is simulated by a stationary random field using the spectral representation method (Shinozuka, 1991). Following Chen (2012), the marginal distribution was chosen as the truncated normal distribution with a mean value of $30 \%$, and the auto-correlation function was chosen as the squared exponential model. The ratio of SOF to specimen diameter is denoted as SOF/D. The natural water content of Singapore upper marine clay ranges from $72 \%$ to $121 \%$ (Xiao, 2009; Zhang et al., 2013). In this study, the water content takes constant 
value of $110 \%$. Other suggested values of parameters of natural cement slurry (Chen, 2012) are constant within the scope of specimen, Table 2. These mean value of binder concentration and soil constants are corresponding to a mix ratio of $2: 1: 3$ where CIU test result is available.

Table 2. Material Parameters for Cement-admixed Soil with Mix Ratio 2:1:3

\begin{tabular}{ccccc}
\hline Parameter & $G_{\mathrm{c}}$ & $\rho\left(\mathrm{g} / \mathrm{cm}^{3}\right)$ & $\rho_{\mathrm{w}}\left(\mathrm{g} / \mathrm{cm}^{3}\right)$ & $w$ \\
\hline Value & 3.15 & 1.6 & 1.0 & $111 \%$ \\
\hline The
\end{tabular}

The mobilized shear strength $\tau_{\mathrm{f}}$ in CIU test is half of the largest deviator stress $\left(q_{\mathrm{f}}\right)$ of the specimen, as shown in Fig. 1. Hence the former shares an identical $\mathrm{COV}$ with the latter and the mean of the former is half that of the latter. In this study, the largest deviator stress $\mathrm{q}_{\mathrm{f}}$ is used.

Spectral Representation Method (SRM) is implemented to generate random field.

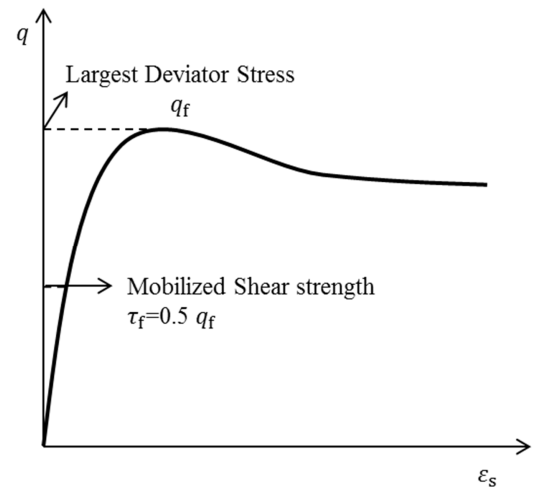

Fig. 1. Definitions of shear strengths.

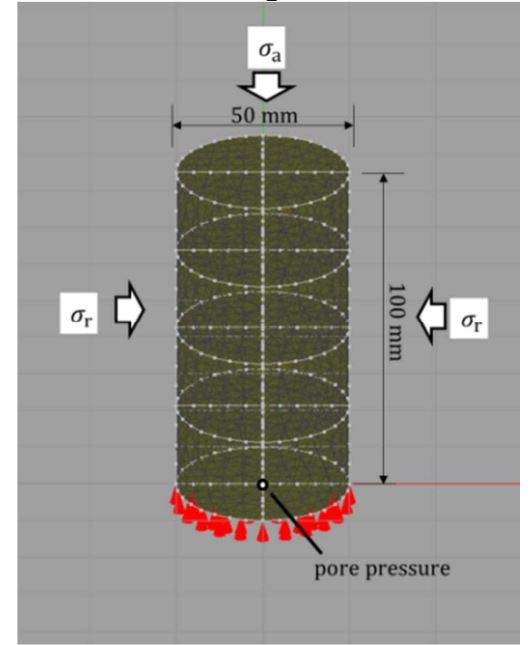

Fig. 2. Modeling of consolidation and undrained shearing

The largest deviator stress is closely related to boundary values. The relationship between binder concentration and largest deviator stress is to be investigated using RFEA. A cylindrical model is adopted to model the specimen using FEM program GeoFEA. The FEA model is shown in Fig. 2, consisting of 4159 quadratic tetrahedron element each of which has ten nodes and eleven integration points, with an average mesh size about $5 \mathrm{~mm}$. The diameter and height of model are identical to conventional triaxial test specimen. The lower boundary is a roller, indicating an ideal loading condition without end restraint effect.

Two steps are involved in each realization, i.e. isotropic consolidation and triaxial undrained shearing.

The initial state of a shearing test corresponds to the end of an isotropic consolidation. This simulation is done by incorporating an advanced constitutive model (Xiao, 2009, 2014) for cement-admixed soil with a fully coupled consolidation analysis into a finite element program GeoFEA. The initial confining pressure of specimen is $5 \mathrm{kPa}$. In consolidation stage, the upper boundary is set permeable which is consistent with real triaxial test. Then the specimen undergoes isotropic loading until it reaches a prescribed confining pressure. To ensure the excess pore pressure is drained, a sufficient long time is assigned in consolidation stage.

After consolidation, the permeable boundary is deactivated and an axial displacement is exerted on top of specimen until the program fails to converge. The strain rate is controlled to be $0.01 \mathrm{~mm} / \mathrm{min}$ which is consistent with Xiao's undrained triaxial test (2009). In this study, 100 realizations are generated for each case.

\section{RESULTS}

\subsection{Effect of SOF on Largest Deviator Stress}

To investigate the effect of SOF on largerst deviator stress, the input COV is kept to be 0.2. The statistical result is shown in Fig. 3. 100 realizations are plotted for each SOF and their mean values are also shown. The mean values of largest deviator stress are all lower than deterministic result $(\mathrm{COV}=0)$ and test result when $\mathrm{SOF} / \mathrm{D}$ is no greater than 1 . This may be because the early local yielding weak zones with this size $(\mathrm{SOF} / \mathrm{D} \leq 1)$ lead to failure of specimen before the other parts yield and weak zones of this size occur in most realizations. As can be seen in Fig. 3, the average of the largest deviator stresses at $\mathrm{SOF} / \mathrm{D}=10$ is larger than the deterministic result, where the former is calculated with $\mathrm{COV}$ of $c_{\text {binder }}=0.2$ and the latter is calculated with $\mathrm{COV}$ of $c_{\text {binder }}=0$.

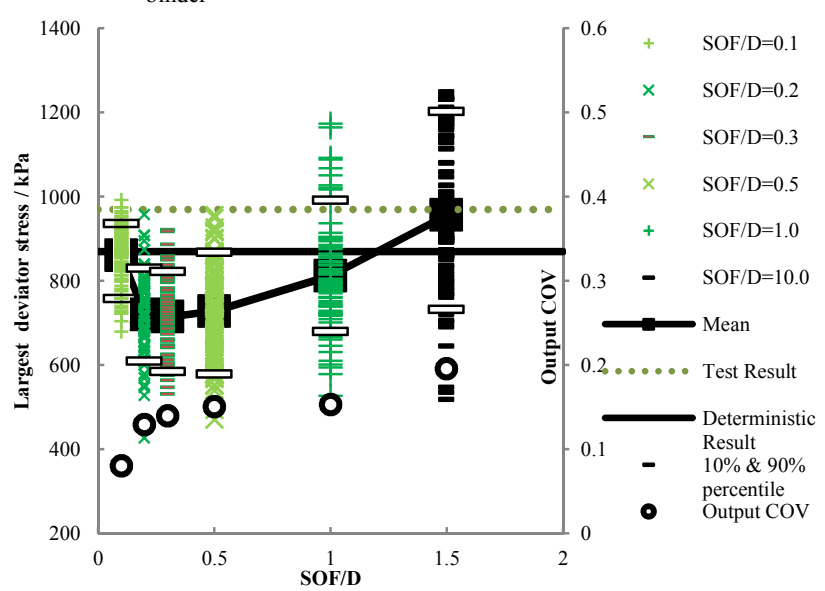

Fig. 3. Sample mean and COV of overall strength with varying 
SOF.

The mean value of largest deviator stress decreases monotonically with SOF/D when SOF/D is smaller than 0.3. This is consistent with Kim and Santamarina's study (2008) which shows a monotonic reduction of mean peak deviator stress as SOF/D increases from 0.01 to 0.16 . The minimum value is obtained when SOF/D is equal to 0.3 in this study while Namikawa and Koseki (2013) found that the minimum unconfined compressive strength is reached when SOF/D is about 1.0. This discrepancy may arise from two differences between this study and Namikawa and Koseki (2013). The first one is the boundary condition difference. Namikawa and Koseki (2013) simulated an unconfined compressive test in which confining pressure does not exist while in this study a confining pressure exists and all the boundaries are closed to drainage during shearing. Secondly, Namikawa and Koseki (2013) used a total-stress constitutive model for cement-treated sand while in this study an effective-stress constitutive model built for cement-treated clay is used.

The degree of variability of largest deviator stress is presented by the $10^{\text {th }}$ and $90^{\text {th }}$ percentiles. It can be observed that the case with $\mathrm{SOF} / \mathrm{D}=0.5$ has the lowest 10th percentile. This means that this case has a higher probability to fail under the same pressure though the case with $\mathrm{SOF} / \mathrm{D}=0.3$ has a lower mean value. The output $\mathrm{COV}$ of largest deviator stress generally increases with SOF/D. This is consistent with Namikawa and Koseki (2013), Ching and Phoon (2013) and Liu (2013).

\subsection{Effect of Input COV on Largest Deviator Stress}

To investigate the effect of $\mathrm{COV}$ on Largest deviator stress, the SOF/D $=0.2$ is kept. The effects of input COV are shown in Fig. 4, which indicates that the mean value of largest deviator stress decreases as the input COV increases. The $10 \%$ percentile also suggest a similar trend. This means for two samples with same

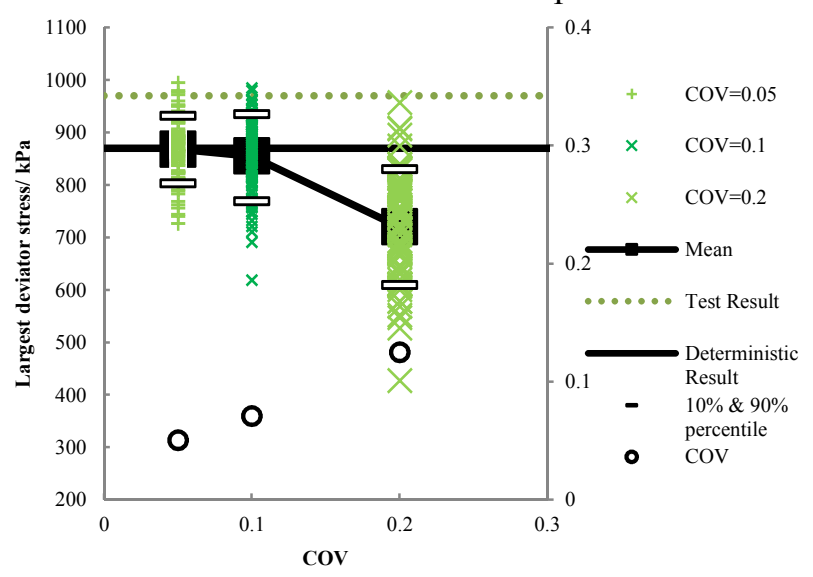

Fig. 4. Sample mean and COV of overall strength with varying $\mathrm{COV}$ of binder concentration. (SOF/D was fixed at 0.2)

mean binder concentration, the one with higher variation amplitude is more likely to have lower global undrained shear strength and therefore the result is likely to deviate more from ideal uniform sample strength. This is consistent with existing studies (Kim and Santamarina, 2008; Namikawa, 2013; Liu, 2013).

\section{CONCLUSIONS}

This study presents a randomized version of an advanced constitutive model for cement-admixed marine clay (Xiao, 2009) by relating all the model parameters to mix ratio and hence binder concentration.

RFEA was conducted on specimen scale to investigate the effect of spatial variability of cementadmixed soil on undrained behaviors. When Input COV is 0.2 , the mean value of largest deviator stress, which is two times that of mobilized shear strength, achieves the minimum value when SOF/D is about 0.3 . The output COV of largest deviator strength generally increases with $\mathrm{SOF} / \mathrm{D}$.

The mean largest deviator stress of specimen decreases monotonically with input COV of binder concentration and the Output COV of largest deviator stress increases with input COV.

\section{ACKNOWLEDGEMENTS}

This research is supported by the National Research Foundation Singapore under its Competitive Research Programme (CRP award no. NRF-CRP 6-2010-03) and the NUS Research Scholarship.

\section{REFERENCES}

1) Chen, J. 2012. Centrifuge model study of mixing quality in wet deep mixing. Ph.D. National University of Singapore.

2) Chen, J., Lee, F.H. \& Ng, C.C. 2011. Statistical analysis for strength variation of deep mixing columns in Singapore. In Han, J. and Alzamora, D.E. (eds.), Geo-Frontiers 2011 Advances in Geotechnical Engineering. Dallas, 13-16. Reston, VA: American Society of Civil Engineering.

3) Ching, J., \& Phoon, K. K. (2013). Mobilized shear strength of spatially variable soils under simple stress states. Structural Safety, 41, 20-28.

4) COI (2005). "Report of the Committee of Inquiry into the Incident at the MRT Circle Line Worksite that led to the Collapse of the Nicoll Highway on 20 April 2004”. Ministry of Manpower, Singapore.

5) Fenton, G. A., \& Griffiths, D. V. (2002). Probabilistic foundation settlement on spatially random soil. Journal of Geotechnical and Geoenvironmental Engineering, 128(5), 381-390.

6) Fenton, G. A., \& Griffiths, D. V. (2003). Bearing-capacity prediction of spatially random $\mathrm{c} \varphi$ soils. Canadian geotechnical journal, 40(1), 54-65.

7) Futaki, M., and Tamura, M. (2002). "The quality control in deep mixing method for the building foundation ground in Japan.” Proc., Tokyo Workshop 2002 on Deep Mixing, Port and Airport Research Institute and Coastal Development Institute of Technology, Tokyo, 139-149.

8) Griffiths DV, Fenton GA. Probabilistic slope stability analysis by finite elements. J Geotech Geoenviron Eng 2004; 130(5): 507-18.

9) Griffiths, D. V., Huang, J., \& Fenton, G. A. (2009). Influence of spatial variability on slope reliability using 2-D random fields. Journal of geotechnical and geoenvironmental 
engineering, 135(10), 1367-1378.

10) Pickles, A. R., \& Henderson, T. O. (2005). Some Thoughts on the Use of Numerical Modelling in Geotechnical Design Practice. Proceedings of Underground Singapore 2005 and Special Session Numerical Analysis in Geotechnical Engineering, 1-2.

11) Honjo, Y. 1982. A probabilistic approach to evaluate shear strength of heterogeneous stabilized ground by deep mixing method. Soils and Foundations 22(1): 23-38.

12) Horpibulsuk S, Miura N, Bergado DT. Undrained shear behaviour of cement admixed clay at high water content. $J$ Geotech Geoenviron Eng, ASCE 2004;130(10):1096-105.

13) Horpibulsuk, S., Liu, M. D., Liyanapathirana, D. S., \& Suebsuk, J. (2010). Behaviour of cemented clay simulated via the theoretical framework of the structured cam clay model. Computers and Geotechnics, 37(1), 1-9.

14) Kim, H. K., \& Santamarina, J. C. (2008). Spatial variability: drained and undrained deviatoric load response. Geotechnique, 58(10), 805.

15) Larsson, S. (2001). Binder distribution in lime - cement columns. Proceedings of the ICE-Ground Improvement, 5(3), 111-122.

16) Larsson, S., Dahlstrom, M., \& Nilsson, B. (2005). Uniformity of lime-cement columns for deep mixing: a field study. Ground Improvement, 9(1), 1-16.

17) Larsson, S., Stille, H., \& Olsson, L. (2005). On horizontal variability in lime-cement columns in deep mixing. Geotechnique, 55(1), 33-44.

18) Lee F. H., Lee Yong, Chew S. H. and Yong K. Y.(2005). "Strength and modulus of marine clay-cement mixes". Journal of Geotechnical and Geoenvironmental Engineering, ASCE, 178-185.

19) Liu, Y. 2013. Random finite element analysis on cementtreated soil layer. Ph.D. National University of Singapore.

20) Lorenzo G. A. and Bergado D. T. (2004). "Fundamental parameters of cement-admixed clay-new approach". Journal of Geotechnical and Geoenvironmental Engineering, ASCE, $1042-1050$.

21) Matsuo, O. (2002). "Determination of design parameters for deep mixing." Proc., Tokyo Workshop 2002 on Deep Mixing, Port and Airport Research Institute andCoastalDevelopment Institute ofTechnology, Tokyo, 75-79.

22) Nakagawa, S., I. Kamegaya, K. Kureha, and T. Yoshida. 1996. Case History and Behavioural Analyses of Braced Large Scale Open Excavation in Very Soft Reclaimed Land in Coastal Area. In Geotechnical aspects of underground construction in soft ground: proceedings of the international symposium on geotechnical aspects of underground construction in soft ground, 179-184. London: A.A. Balkema.

23) Namikawa, T., \& Koseki, J. (2013). Effects of Spatial Correlation on the Compression Behavior of a CementTreated Column. Journal of Geotechnical and Geoenvironmental Engineering, 139(8), 1346-1359.

24) Namikawa, T., \& Mihira, S. (2007). Elasto - plastic model for cement - treated sand. International journal for numerical and analytical methods in geomechanics, 31(1), 71-107.

25) Nobahar, A., and Popescu, P. 2001. "Effects of spatial variability of soil properties on bearing capacity." Proc., 10th Int. Conf. Computer Methods and Advances in Geomechanics, C. S. Desai, T. Kundu, S. Harpalani, D. Contractor, and J. Kemeny, eds., Tucson, Ariz., 1479-1484.

26) Nour, A., Slimani, A., \& Laouami, N. (2002). Foundation settlement statistics via finite element analysis. Computers and Geotechnics, 29(8), 641-672.

27) Omine, K., Ochiai, H., and Yasufuku, N. (2005). "Evaluation of scale effect on strength of cement-treated soils based on a probabilistic failure model." Soils Found., 45(3), $125-134$.

28) O’Rourke, T. D., McGinn, A. J., Dewsnap, J., \& Stewart, H. E. (1998). Case history of an excavation stabilized by deep mixing methods. In Design and Construction of Earth Retaining Systems (pp. 41-62). ASCE.

29) Paice, G. M., Griffiths, D. V., \& Fenton, G. A. (1996). Finite element modeling of settlements on spatially random soil. Journal of Geotechnical Engineering, 122(9), 777-779.

30) Phoon, K. K., \& Kulhawy, F. H. (1999). Characterization of geotechnical variability. Canadian Geotechnical Journal, 36(4), 612-624.

31) Rotta G. V., Consoli N. C., Prietto P. D. M., Coop M .R. and Graham J.(2003). "Isotropic yielding in an artificially cemented soil cured under stress". Geotechnique 53, No. 5, 493-501.

32) Shikauchi, S., H. Osaki, T. Suzuki, and T. Yaoyama. 1993. Analysis of Ground Displacement Due to Large-Scale Excavation for a Tunnel on Tokyo Bay Route, Metropolitan Expressway. In Proceedings of 28th Annual Meething of Japan Society of Soil Mechanics and Froundation Engineering, 1947-1948. JSSMFE. (in Japanese).

33) Shinozuka, M., \& Deodatis, G. (1991). Simulation of stochastic processes by spectral representation. Applied Mechanics Reviews, 44, 191.

34) Suebsuk, J., Horpibulsuk, S., \& Liu, M. D. (2010). Modified structured Cam Clay: a generalised critical state model for destructured, naturally structured and artificially structured clays. Computers and Geotechnics, 37(7), 956-968.

35) Uddin, K., Balasubramaniam A. S. and Bergado D .T. (1997). "Engineering Behavior of Cement-Treated Bangkok Soft Clay". Geotech. Eng., Vol. 28(1), 89-119.

36) Vanmarcke EH. Probabilistic modeling of soil profiles. ASCE J Geotech Eng Div 1977;103(11):1227-46.

37) Xiao H. W., Lee F. H. (2014). An energy-based isotropic compression relation for cement-admixed soft clay. Geotechnique, (accepted).

38) Xiao H. W., Lee F. H., Chin K. G. (2014). Yielding of Cement-Admixed Marine Clay. Soils and Foundations, (Accepted)

39) Xiao H.W. 2009. Yielding and failure of cement treated soil. Ph.D Thesis. National University of Singapore.

40) Zhang, R. J., Santoso, A. M., Tan, T. S., \& Phoon, K. K. (2013). Strength of High Water-Content Marine Clay Stabilized by Low Amount of Cement. Journal of Geotechnical and Geoenvironmental Engineering, 139(12), 2170-2181. 